\title{
GUIDELINES TO AUTHORS
}

1. Papers for publication should be sent in quadruplicate to one of the Editors:

$\begin{array}{ll}\text { Andrew Cairns } & \text { Paul Embrechts } \\ \text { Department of Actuarial Mathematics } & \text { Department of Mathematics } \\ \text { and Statistics } & \text { ETHZ } \\ \text { Heriot-Watt University } & \text { CH-8092 Zurich, Switzerland. } \\ \text { Edinburgh EH14 4AS, United Kingdom } & \text { embrechts@math.ethz.ch }\end{array}$

A.Cairns@ma.hw.ac.uk

Submission of a paper is held to imply that it contains original unpublished work and is not being submitted for publication elsewhere.

Receipt of the paper will be confirmed and followed by a refereeing process, which will take about three months.

2. The basic elements of the journal's style have been agreed by the Editors and Publishers and should be clear from checking a recent issue of ASTIN BULLETIN. If variations are felt necessary they should be clearly indicated on the manuscript.

3. Papers should be written in English or in French. Authors intending to submit longer papers (e.g. exceeding 30 pages) are advised to consider splitting their contribution into two or more shorter contributions.

4. The first page of each paper should start with the title, the name(s) of the author(s), and an abstract of the paper as well as some major keywords. An institutional affiliation can be placed between the name(s) of the author(s) and the abstract.

5. Footnotes should be avoided as far as possible.

6. References should be arranged alphabetically, and for the same author chronologically. Use a, b, c, etc. to separate publications of the same author in the same year. For journal references give author(s), year, title, journal (in italics, cf. point 9), volume (in boldface, cf. point 9), and pages. For book references give author(s), year, title (in italics), publisher, and city.

Examples

Barlow, R.E. and Proschan, F. (1975) Mathematical Theory of Reliability and Life Testing. Holt, Rinehart, and Winston, New York.

Jewell, W.S. (1975a) Model variations in credibility theory. In Credibility: Theory and Applications (ed. P.M. KAHN), pp. 193-244, Academic Press, New York.

JEWELL, W.S. (1975b) Regularity conditions for exact credibility. ASTIN Bulletin 8, 336-341. References in the text are given by the author's name followed by the year of publication (and possibly a letter) in parentheses.

7. The address of at least one of the authors should be typed following the references.

8. Italics (boldface) should be indicated by single (wavy) underlining. Mathematical symbols will automatically be set in italics, and need not be underlined unless there is a possibility of misinterpretation. Information helping to avoid misinterpretation may be listed on a separate sheet entitled 'special instructions to the printer'. (Example of such an instruction: Greek letters are indicated with green and script letters with brown underlining, using double underlining for capitals and single underlining for lower case). 
9. Contributions must be typewritten on one side of good quality paper, with double spacings and ample margins all round.

Illustrations should be submitted as clear black and white prints. Photocopies are not acceptable. Line thickness and lettering size should be adopted to suit any likely degree of reduction.

Each contribution should obtain the author(s) full address(es), including e-mail and fax numbers when available. Authors should notify the publisher whenever their contact details change.

A copy of text should also be submitted on disk, when available. Please state clearly the type of software used, and note the filename. Contributors should also retain a copy of their article.

Two sets of proofs will be shipped to authors who should ensure that one set plus the manuscript is returned to PEETERS within one week of receipt. Authors may be charged for alterations to the original manuscript. If authors proofs are not returned by the required date, the publisher's own corrected set will be forwarded to the printer.

10. Authors will receive 30 offprints free of charge. Additional offprints may be ordered when returning corrected proofs. A scale of charges will be enclosed when the proofs are sent out. 